\title{
An Investgation About the Relationship Between Vasopressin and Oxytocin in Persistent Type Functional Neurological Symptom Disorder
}

\author{
Bahar Yeşil Örnek $^{1}$, Birgül Elbozan Cumurcu², and Esra Porgali Zayman² \\ ${ }^{1}$ Dr. Abdurrahman Yurtaslan Oncology Research and Training Hospital Psychiatry Departmant, University Health Sciences, Ankara, Turkey \\ ${ }^{2}$ Inonu University, Medicine Faculty, Psychiatry Departmant, Malatya, Turkey
}

\begin{abstract}
Objective Functional neurogical symptom disorder (FNSD) is a somatic symptom disorder with loss of voluntary motor or sensory functions, which cannot be explained by another medical condition. The study aimed to examine the relationship of vasopressin and oxytocin in persistent type FNSD.

Methods This study included 27 female patients between the ages of 20-57 who were diagnosed with FNSD according to DSM- 5 and 27 healthy controls matched in terms of age and gender. Serum vasopressin and oxytocin levels were measured twice on the same day in fasting blood samples and the results were compared statistically.

Results Vasopressin were lower in patients compared to controls while there was no difference between oxytocin levels. Childhood traumas were more common in patient group, and mean oxytocin level was lower in patients who exposed to childhood trauma, compared to controls. No significant difference was found between the groups in terms of vasopressin.

Conclusion Changes in vasopressin and oxytocin balance in the pathogenesis of persistant FNSD, may likely to lead to physiological and behavioral consequences. Lower oxytocin levels may also be a marker of exposure to childhood trauma in FNSD. These neuropeptides plays important role in neuroendocrine balance of emotional behavior.

Psychiatry Investig 2021;18(10):1018-1024
\end{abstract}

Keywords Oxytocin; Vasopressin; Functional neurological symptom disorder; Childhood trauma.

\section{INTRODUCTION}

Functional neurological symptom disorder (FNSD) is a somatic symptom disorder, in which clinical symptoms cannot be explained by another neurological or medical condition or mental illness and progress with loss of voluntary motor or sensory functions. ${ }^{1}$ Symptoms include weakness, paralysis, difficulty swallowing, unusual speech and sensory symptoms, and drowsiness or mixed symptoms. ${ }^{2}$ Its prevalence has been reported to be $1 \%-3 \%$ in the developed countries and approximately $10 \%$ in the developing countries. In Turkey, the prevalence of it has been reported in a wide range ranging from

Received: February 3, 2021 Revised: February 23, 2021

Accepted: June 30, 2021

$\triangle$ Correspondence: Bahar Yesil Örnek, MD, PhD

Psychiatry Department, Dr. Abdurrahman Yurtaslan Oncology Research and Training Hospital, University of Health Sciences, Mehmet Akif Ersoy Mah. Vatan Cad. No :91 Yenimahalle/Ankara, Turkey

Tel: +905538663544, Fax: +90312 33433 52, E-mail: baharyesilege@gmail.com

(c) This is an Open Access article distributed under the terms of the Creative Commons Attribution Non-Commercial License (https://creativecommons.org/licenses/bync/4.0) which permits unrestricted non-commercial use, distribution, and reproduction in any medium, provided the original work is properly cited.
$4.5 \%-32 \%$, in adults. It is most frequently seen between the ages of $15-35$, while the female/male sex ratio has been reported to be $2-10: 1 .^{3}$

Exaggerated or prolonged stress may predispose to mental illnesses by causing pathophysiological changes in the brain and immune system. ${ }^{4}$ In the studies conducted in Turkey, it has been shown that stress factors were present in $17 \%-45 \%$ of the cases before the development of FNSD. ${ }^{5}$ Stressful life events and mental conflicts can trigger the symptoms. Distressing stimuli, personality patterns that facilitate expression through psychosomatic means, personality disorders, traumatic experiences, communication problems, psychiatric or neurobiological disorders are predisposing factors for FNSD. ${ }^{6}$ However, the mechanism of the neuroendocrine regulation associated with the stress response has not been clearly explained yet. Vasopressin and oxytocin hormones, which are synthesized in the paraventricular (PVN) and supraoptic (SCN) cores of the hypothalamus and released into the brain and peripheral circulation through the posterior pituitary, take part in the stress response cycle by mutual interaction. ${ }^{7}$ Both oxy- 
tocin and vasopressin receptors are found abundant in the nervous system regions that regulate social, emotional, and adaptive behaviors, including the amygdala, the HPA axis, and the autonomic nervous system. ${ }^{8}$ Oxytocin has been shown to be related with behavioral aspects that include attachment, affiliation, prosocial behavior, stress regulation, memory and learning under very stressful conditions, especially social learning. ${ }^{9}$ The increase in plasma oxytocin has been found to be associated with the weakening of the hormonal response that occurs after stress and a decrease in anxiety. ${ }^{10}$ Stress-protective and anxiolytic properties of oxytocin have been shown in studies conducted on animal models. ${ }^{11}$ Conversely, decreased oxytocin levels have been found to be associated with psychiatric diseases such as depression, schizophrenia, and autism spectrum disorder. ${ }^{12}$ In animal experiments, it has been shown that the stress- protective effects of oxytocin are resulted from its regulating action in the hypopituitary-pituitary-adrenal (HPA) axis. ${ }^{13}$ In addition, usually, oxytocin does not act alone, interactions between vasopressin and oxytocin help to explain the importance of social behavior in the regulation of anxiety and responses to threats, which in some cases are promoted by vasopressin. ${ }^{14}$

Vasopressin plays a role in emotional behavior including fear, anxiety and aggression as well as its effects on fluid hemostasis and regulation of blood pressure. Increases in autonomic responses to social threats and anxiety have been associated with vasopressin. ${ }^{15}$ In males, vasopressin was shown to cause aggressive behavioral response to social stimulus. ${ }^{16,17} \mathrm{On}$ the other hand, oxytocin is a component of social and passive coping skills and allows active and mobilized coping strategies through interaction with vasopressin. ${ }^{18}$ To the best of our knowledge, in the literature, there is no study investigating the roles of oxytocin and vasopressin in the pathogenesis of FNSD.

In our study, we hypothesized that oxytocin levels might be lower in FNSD and the balance between oxytocin and vasopressin may have altered, considering the stress-balancing effects of oxytocin and also interaction between these hormones. We believe that understanding the roles of oxytocin and vasopressin in the stress response will contribute to the understanding of FNSD pathophysiology. The aim of this study is to determine how oxytocin and vasopressin levels are affected in persistent FNSD patients compared to controls.

\section{METHODS}

This study included 27 female patients between the ages of 20 and 57 years, who admitted to the Turgut Ozal Medical Center Psychiatry Outpatient Clinic with conversion seizures and were diagnosed with FNSD with debility or stroke (paralysis) according to DSM-5, and 27 healthy controls, who were matched by age and gender. Males were also invited to the study; however the number of patients was not sufficient to be evaluated statistically. Patients with chronic medical diseases, neurological diseases, alcohol and other substance dependence (excluding smoking), and a history of drug use during the last six months were excluded from the study. The control group included healthy subjects without a medical disease, without an axis I diagnosis according to DSM-5, and with no first-degree relatives with any psychiatric disease. The patient and control groups were evaluated according to DSM- 5 by a face to face interview conducted by a psychiatrist and laboratory tests were performed. Childhood trauma variable, "Have you ever experienced an event in your childhood ( $<18$ years) that affected you mentally such as neglect, accident, loss of parents, sexual trauma, etc.?" questioned by the question. This study was conducted in accordance with the Declaration of Helsinki and approval was obtained from the Ethics Committee of Inonu University Faculty of Medicine, dated 03.05.2011, number 2011/40. Informed written consent was obtained from all participants.

\section{Measurement of serum vasopressin (antidiuretic hormone) and oxytocin levels}

Fasting blood samples taken from the antecubital vein into the biochemistry tube were centrifuged at 3,000 rpm for 10 minutes, and serum was obtained and stored at $-70^{\circ} \mathrm{C}$ until evaluation (the longest period would be one year). Vasopressin and oxytocin measurements were made twice on the same day, in order to reduce technical and personal bias. Commercial ELISA kits (CUSABIO Biotech Co., Wuhan, China) were used for measurements.

\section{Statistical analysis}

Data were analyzed by using Statistical Package for the Social Sciences (SPSS) version 21.0 (IBM Corp., Armonk, NY, USA). The patients' age, duration of education, duration of disease, and age at onset of disease were presented as mean and standard deviation. Categorical data were expressed by numbers and percentages. The normality of distribution was tested by Shaphiro Wilks tests. Chi-square test was used in categorical data analysis. Group differences in continuous variables were analyzed using independent-sample t-test when the normality condition was provided. In addition, continuous variables (age, age of onset, and duration of the disease) were compared by using Pearson's correlation analysis.

\section{RESULTS}

The sample of this study consisted of 27 female patients diagnosed with FNSD and 27 healthy controls. Mean age was 
$30.22 \pm 9.18$ years in the patient group and $29.62 \pm 9.16$ years in the control group; mean duration of education was $8.00 \pm 4.67$ years in the patient group and $14.92 \pm 3.57$ years in the control group. There was no significant difference between the groups in terms of age, while the duration of education was significantly longer in the control group compared to the patient group ( $\mathrm{p}=0.84, \mathrm{p}=0.001$, respectively). The ratio of those working in a regular job (yes/no), education status (literate/illiterate) was lower ( $\mathrm{p}=0.001, \mathrm{p}=0.001$, respectively), and raising up in rural areas and still living there was higher in the patient group compared to the healthy controls ( $\mathrm{p}=0.001, \mathrm{p}=0.001$, respectively) (Table 1). Table 2 shows the frequency of the variables related with FNSD including frequency of disease symptoms (once a month or less, more than once a month), presence of pre-symptom stress factors, and a history of medical treat-

Table 1. Sociodemographic characteristics of the patient and control groups

\begin{tabular}{|c|c|c|c|c|}
\hline Variable & $\begin{array}{c}\text { Patient }(\mathrm{N}) \\
(\%)\end{array}$ & $\begin{array}{c}\text { Control (N) } \\
(\%)\end{array}$ & $\chi^{2}$ & $\mathrm{p}$ \\
\hline \multicolumn{3}{|l|}{ Marital status } & 0.701 & 0.402 \\
\hline Single & $18(66.7)$ & $15(55.6)$ & & \\
\hline Married & $9(33.3)$ & $2(44.4)$ & & \\
\hline \multicolumn{3}{|l|}{ Education status } & 19.316 & $0.001^{*}$ \\
\hline Literate & $11(40.7)$ & $26(96.3)$ & & \\
\hline Illiterate & $16(59.3)$ & $1(40.7)$ & & \\
\hline \multicolumn{3}{|c|}{ Working in a regular job } & 15.565 & $0.001^{*}$ \\
\hline Yes & $3(88.9)$ & $17(63.0)$ & & \\
\hline No & $24(11.1)$ & $10(37.0)$ & & \\
\hline \multicolumn{3}{|l|}{ Living place } & 13.886 & $0.001^{*}$ \\
\hline Urban & $14(51.9)$ & $1(3.7)$ & & \\
\hline Rural & $13(48.1)$ & $26(96.3)$ & & \\
\hline \multicolumn{3}{|l|}{ Raising place } & 6.312 & $0.001^{*}$ \\
\hline Urban & $12(44.4)$ & $21(77.8)$ & & \\
\hline Rural & $15(55.6)$ & $6(22.7)$ & & \\
\hline \multicolumn{3}{|c|}{ History of mental disease } & 1.477 & 0.22 \\
\hline Yes & $5(18.5)$ & $2(7.3)$ & & \\
\hline No & $22(81.5)$ & $25(92.7)$ & & \\
\hline \multicolumn{3}{|c|}{ Family history of mental disease } & 0.491 & 0.48 \\
\hline Yes & $6(22.2)$ & $4(14.82)$ & & \\
\hline No & $21(77.8)$ & $23(85.18)$ & & \\
\hline \multicolumn{3}{|l|}{ Smoking } & 1.714 & 0.19 \\
\hline Yes & $8(29.6)$ & $4(14.82)$ & & \\
\hline No & $16(70.4)$ & $23(85.18)$ & & \\
\hline \multicolumn{3}{|c|}{ Childhood trauma } & 6.577 & $0.01^{*}$ \\
\hline Yes & $14(51.9)$ & $5(18.5)$ & & \\
\hline No & $13(48.1)$ & $19(81.5)$ & & \\
\hline
\end{tabular}

ment and FNSD subtypes (motor, sensory, seizure or mixed symptoms).

In our study, serum vasopressin levels were statistically significantly lower in the patient group compared to the control group ( $\mathrm{p}=0.019)$. Oxytocin levels were also relatively higher in the patient group, however the difference was not statistically significant ( $\mathrm{p}=0.26$ ) (Table 3 ).

Childhood traumas, including separation from the mother, disintegrated family and known history of sexual trauma were more common in the patient group compared to the control group $(\mathrm{p}=0.01)$. The mean level of oxytocin was lower in patients with a history of a childhood trauma compared to the control group ( $p=0.09$ ), whereas there was no significant difference between the groups in terms of vasopressin levels $(\mathrm{p}=0.53)$ (Table 4).

The mean duration of disease was found to be $30.25 \pm 28.24$ months and the mean age at onset of the disease was 25.27士 10.40 years in the patient group. Since the mean duration of disease was $>6$ months in our sample, the patients in our study were classified as "persistent type FNSD" according to DSM-5 criteria. The duration of disease was not found to be associated with oxytocin and vasopressin levels ( $p>0.05)$. We found that, there was a negative correlation between the oxytocin

Table 2. Patient variables related to FNSD

\begin{tabular}{lc}
\hline \multicolumn{1}{c}{ Variable } & Patient (N) (\%) \\
\hline Pre-symptom stressor factor & $22(81.48)$ \\
Yes & $5(18.52)$ \\
No & \\
Frequency of symptoms & $6(22.7)$ \\
Once a mont or less & $21(77.8)$ \\
More than once a month & \\
Subtype of FNSD & $6(22.2)$ \\
With weakness/paralysis & $2(7.4)$ \\
With anesthesia/sensory loss & $17(63.0)$ \\
With abnormal movement & $2(7.4)$ \\
With mixed symptoms & \\
History of pharmalogical treatment & $23(86.5)$ \\
Yes & $4(13.5)$ \\
No
\end{tabular}

FNSD, functional neurological symptom disorder

Table 3. Oxytocin and vasopressin levels of patient and control group

\begin{tabular}{lcccl}
\hline & $\mathrm{N}$ & $\begin{array}{c}\text { Patient } \\
(\mathrm{Mean} \pm \mathrm{SD})\end{array}$ & $\begin{array}{c}\text { Control } \\
(\mathrm{Mean} \pm \mathrm{SD})\end{array}$ & $\mathrm{p}$ \\
\hline Oxytocin & 27 & $45.85 \pm 24.56$ & $38.40 \pm 23.78$ & 0.26 \\
Vasopressin & 27 & $13.00 \pm 4.14$ & $16.22 \pm 5.52$ & $0.019^{*}$ \\
\hline
\end{tabular}

${ }^{*} \mathrm{p}<0.05$ statistical significance value. SD, standard deviation 
Table 4. Oxytocin and vasopressin levels in patients with presence of childhood trauma $(\mathrm{N}=27)$

\begin{tabular}{ccccc}
\hline Childhood trauma & $\mathrm{N}(\%)$ & Oxytocin $($ Mean \pm SD) & $\mathrm{p}$ & Vasopressin $($ Mean \pm SD) \\
\hline Yes & $14(51.85)$ & $38.00 \pm 18.88$ & $0.09^{*}$ & $13.50 \pm 3.39$ \\
No & $13(48.15)$ & $54.30 \pm 27.78$ & & $12.46 \pm 4.90$ \\
\hline
\end{tabular}

${ }^{*} \mathrm{p}<0.05$ statistical significance value. SD, standard deviation

levels and the age of patients and the age of onset $(\mathrm{p}=0.008, \mathrm{r}=$ 0.497 and $\mathrm{p}=0.01, \mathrm{r}=470$, respectively), whereas no relationship was found between the vasopressin levels and the age of the patients or age of onset.

\section{DISCUSSION}

Oxytocin and vasopressin are neuromodulators that play a role in the regulation of lifelong social behaviors and provide mechanisms to be prepared for and to adapt to life's difficulties. In this study, serum oxytocin and vasopressin levels of 27 female patients with FNSD 27 age and sex matched healthy controls were compared in terms of clinical and individual variables. Our sample consisted of FNSD patients with a duration of disease longer than 6 months and no history of treatment for the last 6 months. To the best of our knowledge, in the literature, there is no study investigating oxytocin and vasopressin levels in FNSD patients. In the clinic picture of FNSD, initiating stressors may play a role and anxiety and depression symptoms may accompany. Vasopressin is a peptide that plays a role in the regulation of various social behaviors such as intimacy, mate attachment, and aggression, and may have a role in the increasing tendency to anxiety and depression. In addition, vasopressin receptors found to be associated with social recognition memory and social aggression pattern. ${ }^{19}$ In our study, serum vasopressin levels of FNSD patients were found to be lower compared to the healthy controls ( $p=0.019)$. In participants with an average duration of illnesses of longer than 24 months, the mean level of vasopressin, which is known to be an activator of the HPA axis, may have been found low due to prolonged and intense stress perception. In an animal study that supports our results, a significant decrease in salivary vasopressin levels was found after intense exposure to stress, however vasopressin levels were not affected at low exposure to stress. ${ }^{20}$ In FNSD patients, especially in the chronic period, stress tolerance decreases and stress management is impaired. Vasopressin, which is associated with anxiety and mobilization, is known to allow more active coping skills. ${ }^{21}$

In addition, vasopressin improves threat perception abilities. ${ }^{22}$ According to our results, FNSD patients may have difficulty perceiving or detecting threats from the external environment associated with lower vasopressin levels. ${ }^{22}$ Low levels of vasopressin may lead to inability to activate coping skills, and may also be associated with vulnerability to mental illness. This may be an important reason for the inadequacy of psychotherapeutic interventions in persistent FNSD.

In contrast to vasopressin, oxytocin, which is defined as a social hormone, is involved in anxiety regulation, coping with stress and social communication, in mammals, primates, and humans. ${ }^{23}$ Contrary to our hypothesis, we could not find a significant difference between the patient group and the control group in terms of oxytocin levels. Primarily, conducted on female patients, oxytocin levels may be affected by individual factors other than the disease. ${ }^{24}$ Gender differences, individual factors, positive or negative life experiences and social interactions can lead to changes in oxytocin level. ${ }^{25}$ Studies have found that oxytocin expression is generally higher in females. ${ }^{26}$ It is known that co-activation of the HPA axis and oxytocin occurs immediately after the onset of stress, in the early phase and leads to a rapid recovery. ${ }^{27}$ It is also known that oxytocin can regulate vasopressin activity. ${ }^{19}$ In addition, acute and chronic stress produces physiologically distinct adaptive responses. ${ }^{28}$ In most cases, oxytocin release continues against a chronic stress that may follow acute stress. ${ }^{29}$ However, we found no difference in terms of oxytocin levels. In our study, it is possible that oxytocin, which may have increased in the early stage, returned to stable levels in the chronic period.

An important finding of our study, the mean oxytocin level was lower in patients with both persistent FNSD and childhood trauma compared to controls $(\mathrm{p}=0.09)$, however, no significant difference was found between the whole FNSD group and healthy controls. Childhood trauma is associated with impaired recognition and expression of feelings, impaired emotion regulation, problems in attachment and interpersonal relationships. ${ }^{30}$ Traumatic and stressful experiences may lead to hormonal changes, primarily hypo- or hyper activity in the HPA axis. Dysfunction in HPA axis contributes to weakening of the immune system, to increased vulnerability to psychopathologies, and to the inability to cope with stressful/traumatic events. ${ }^{31}$ Evidence suggests that oxytocin release plays role in regulating cortisol levels that allow the body to rapid return to its pre-stressed state. ${ }^{27,32}$ Also, stressful experiences might affect the function of the suprachiasmatic nucleus and lead to reduce endogenous oxytocin release and synthesis. ${ }^{33,34}$ Women with childhood abuse and higher anxiety levels found to have lower oxytocin release in the cerebrospinal fluid with 
increased anxiety. ${ }^{35}$ Another study found lower oxytocin levels associated with more severe prepubertal stressors in adult males. Also, oxytocin pathway alters in response to early life trauma in adults and children. ${ }^{36}$ Furthermore, intranasal administration of oxytocin may decrease stress reactivity, ${ }^{27}$ as well as salivary cortisol levels. ${ }^{37}$ In addition to its physiological roles, oxytocin could facilitate passive coping skills, which are important during exposure to chronic stress, and protect against inactivity in the face of fear. ${ }^{38}$ In our study, the low levels in serum oxytocin, may reduce the pro-social functions of FNSD patients, thereby reducing coping and resilience mechanisms. Ineffective regulation for stress could lead to common interpersonal difficulties and impaired stress regulation in FNSD patients. Low oxytocin may be associated with problems in attachment and difficulty in interpersonal relations. ${ }^{39}$ In this context, traumatic experiences are known to play role in vulnerability to mental illness. ${ }^{36} \mathrm{FNSD}$ patients without trauma exposure may benefit better from the anti-stress effects of oxytocin. FNSD patients who exposed to childhood trauma appear physiologically more vulnerable to stress. Lower serum oxytocin levels may be an indicator of early age trauma in persistent FNSD.

In contrast to oxytocin, no significant difference was found in terms of vasopressin levels, between groups with childhood trauma. When exposed to early life stress, vasopressin improves threat perception abilities, while oxytocin protects social bonds. ${ }^{22}$ Oxytocin and vasopressin increase alertness to threats and support survival for those who experience intense stress in early life. ${ }^{27}$ It was reported that vasopressin expression increased after neglect or other negative social experiences at an early age. ${ }^{40}$ Adversities in early life sensitize the vasopressin system and regulate the AVPR1A receptor. ${ }^{41}$ Conversely, in the presence of low early life stress, vasopressin creates a less alert response to threat and consequently maintains metabolic energy. ${ }^{28}$ The lower serum vasopressin levels, we found in FNSD patients, was not different in those exposed to trauma. Our result may point to an adaptation mechanism associated with the increase serum vasopressin in those with childhood trauma. We thought that there might be an enhanced threat expectation associated with the increase in vasopressin after exposed to traumatic events. This adaptation may associated with either a more active or mobilized defensive behavior or aggressive behavior later in life. ${ }^{22}$ Vasopressin may have a modulator role in threat perception, security behavior and coping with stress. In addition, our results suggest that vasopressin has regulatory effects on chronic (> 6 months) stress response.

In our study, similar to the literature, we found that the frequency of FNSD was higher in the population with a low education level, in those living in rural areas, unmarried, and those without a regular job. ${ }^{42}$ In the literature, it was reported that living in rural areas, living under low socioeconomic conditions, having a low education level, and having an insufficient insight and low intelligence level are risk factors for FNSD.? It is also possible that individual factors may be perceived by patients as cumulative stress. Cumulative stress has different effects than acute stress. A recent study found that cumulative stress associated with PTSD and anxiety caused impairment in the neural pathways, associated with endurance in adulthood through the oxytocin and AVP pathway. ${ }^{43}$

The limitations of our study include the limited number of cases, the absence of male patients and the lack of evaluation in the acute period. Our results are difficult to generalize due to the fact that our sample was consisted of female patients. However, an important point is that oxytocin and vasopressin are hormones with different expressions according to gender. ${ }^{25}$ It was reported that females were found to be twice as likely to be exposed to trauma or other adversities generally. They are significantly more vulnerable to disorders such as depression and post-traumatic stress disorder. ${ }^{44}$ In this context, it is thought that defects in oxytocin and vasopressin or their receptors are more likely to affect women. It is important to study a single sex, as in our research, to exclude a confounding factor such as gender.

In conclusion, the results of our study comparing oxytocin and vasopressin levels in FNSD patients and healthy controls suggest that oxytocin and vasopressin may have a role in the pathogenesis of FNSD. As an important finding low oxytocin levels may be and indicator of childhood trauma in FNSD, and may play a role in vulnerability to FNSD patients who exposed to early life trauma. The mutual interaction of these two peptide hormones may have an important role in neuroendocrine balance for emotional behavior. Therefore, in order to understand the role of neuromodulators in FNSD, prospective studies with large samples and including both genders and investigating both acute and persistent cases are needed.

\section{Availability of Data and Material}

The datasets generated or analyzed during the study are available from the corresponding author on reasonable request.

\section{Conflicts of Interest}

The authors have no potential conflicts of interest to disclose.

\section{Author Contributions}

Conceptualization: Birgül Elbozan Cumurcu. Data curation: Bahar Yeşil Örnek, Esra Porgalı Zayman. Formal analysis: Bahar Yeşil Örnek. Investigation: Esra Porgalı Zayman. Methodology: Birgül Elbozan Cumurcu. Project administration: Bahar Yeşil Örnek. Resources: Esra Porgalı Zayman. Software: Bahar Yeşil Örnek. Supervision: Birgül Elbozan Cumurcu. Validation: Bahar Yeşil Örnek. Visualization: Esra Porgalı Zayman. Writingoriginal draft: Bahar Yeşil Örnek. Writin—review\&editing: Birgül Elbozan Cumurc. 


\section{ORCID iDs}

Bahar Yeşil Örnek

Birgül Elbozan Cumurcu

Esra Porgali Zayman

https://orcid.org/0000-0003-0873-4589

https://orcid.org/0000-0001-9289-837X

https://orcid.org/0000-0003-1551-6782

\section{Funding Statement}

This study was supported by Scientific Research Fund of Inonu University (IUBAP) under Grant 2013/81 number.

\section{REFERENCES}

1. American Psychiatric Association. Diagnostic and Statistical Manual of Mental Disorders (DSM-5) (5th Ed). Arlington: American Psychiatric Pub; 2013.

2. Espay AJ, Aybek S, Carson A, Edwards MJ, Goldstein LH, Hallett M, et al. Current concepts in diagnosis and treatment of functional neurological disorders. JAMA Neurol 2018;75:1132-1141.

3. Şar V. The scope of dissociative disorders: an international perspective. Psychiatr Clin North Am 2006;29:227-244.

4. Liu YZ, Wang YX, Jiang CL. Inflammation: the common pathway of stress-related diseases. Front Hum Neurosci 2017;11:316.

5. Özen Ş, Özbulut Ö, Altındağ A, Arıcıoğulları Z. Sociodemographic characteristics, stress factors of patients diagnosed with conversion disorder in the emergency department, I. and II. axis co-diagnoses. Türkiyede Psikiyatri 2000;2:87-96.

6. Köroğlu E, Güleç C, Şenol S. Basic Book of Psychiatry. Ankara: HYB Publishing; 2007.

7. Meyer-Lindenberg A, Domes G, Kirsch P, Heinrichs M. Oxytocin and vasopressin in the human brain: social neuropeptides for translational medicine. Nat Rev Neurosci 2011;12:524-538.

8. Gobrogge KL, Jia X, Liu Y, Wang Z. Neurochemical mediation of affiliation and aggression associated with pair-bonding. Biol Psychiatry 2017; 81:231-242.

9. Seng J, Miller J, Sperlich M, van de Ven CJ, Brown S, Carter CS, et al. Exploring dissociation and oxytocin as pathways between trauma exposure and trauma-related hyperemesis gravidarum: a test-of-concept pilot. J Trauma Dissociation 2013;14:40-55.

10. Matsushita H, Latt HM, Koga Y, Nishiki T, Matsui H. Oxytocin and stress: neural mechanisms, stress-related disorders, and therapeutic approaches. Neuroscience 2017;417:1-10.

11. Peters S, Slattery DA, Uschold-Schmidt N, Reber SO, Neumann ID. Dose-dependent effects of chronic central infusion of oxytocin on anxiety, oxytocin receptor binding and stress-related parameters in mice. Psychoneuroendocrinology 2014;42:225-236.

12. Cochran D, Fallon D, Hill M, Frazier JA. The role of oxytocin in psychiatric disorders: a review of biological and therapeutic research findings. Harvard Rev Psychiatry 2013;21:219.

13. Apazoglou K, Adouan W, Aubry JM, Dayer A, Aybek S. Increased methylation of the oxytocin receptor gene in motor functional neurological disorder: a preliminary study. J Neurol Neurosurg Psychiatry 2018;89: 552-554.

14. Neumann ID, Slattery DA. Oxytocin in general anxiety and social fear: a translational approach. Biol Psychiatry 2016;79:213-221.

15. Jeong YK, Oh YI, Song KH, Seo KW. Evaluation of salivary vasopres$\sin$ as an acute stress biomarker in healthy dogs with stress due to noise and environmental challenges. BMC Veter Res 2020;16:1-9.

16. Thompson RR, K George JC, Walton SP, Orr SP, Benson J. Sex-specific İnfluences of vasopressin on human social communication. Proc Natl Acad Sci U S A 2006;103:7889-7894.

17. Viviani D, Stoop R. Opposite effects of oxytocin and vasopressin on the emotional expression of the fear response. Prog Brain Res 2008;170:207218.

18. Søgaard U, Mathiesen BB, Simonsen E. Personality and psychopathology in patients with mixed sensory-motor functional neurological dis- order (conversion disorder): a pilot study. J Nerv Ment Dis 2019;207: 546-554.

19. Caldwell HK, Aulino EA, Rodriguez KM, Witchey SK, Yaw AM. Social context, stress, neuropsychiatric disorders, and the vasopressin $1 \mathrm{~b}$ receptor. Front Neurosci 2017;11:567.

20. Carter CS, Grippo AJ, Pournajafi-Nazarloo H, Ruscio MG, Porges SW. Oxytocin, vasopressin and sociality. Progress Brain Res 2008;170:331336.

21. Koolhaas JM, Everts H, De Reuter AJ, De Boer SF, Bohus B. Coping with stress in rats and mice: differential peptidergic modulation of the amygdala-lateral septum complex. Progress Brain Res 1999:119;437448

22. Perry-Paldi A, Hirschberger G, Feldman R, Zagoory-Sharon O, Buchris Bazak S, Ein-Dor T. Early environments shape neuropeptide function: the case of oxytocin and vasopressin. Front Psychol 2019;10:581.

23. Neumann ID, Landgraf R. Balance of brain oxytocin and vasopressin: implications for anxiety, depression, and social behaviors. Trends Neurosci 2012;35: 649-659.

24. Bell AF, Carter CS, Steer CD, Golding J, Davis JM, Steffen AD, et al. Interaction between oxytocin receptor DNA methylation and genotype is associated with risk of postpartum depression in women without depression in pregnancy. Front Genet2015;6:243.

25. Say GN, Müjdeci M. Oxytocin and psychiatric disorders. Psikiyatride Güncel Yaklaşımlar 2016;8:102-113.

26. Dumais KM, Veenema AH. Vasopressin and oxytocin receptor systems in the brain: sex differences and sex-specific regulation of social behavior. Front Neuroendocrinol 2016;40:1-23.

27. Heinrichs M, Baumgartner T, Kirschbaum C, Ehlert U. Social support and oxytocin interact to suppress cortisol and subjective responses to psychosocial stress. Biol Psychiatry 2003;54:1389-1398.

28. Carter CS, Kenkel WM, MacLean EL, Wilson SR, Perkeybile AM, Yee JR, et al. Is Oxytocin "Nature's Medicine"? Pharmacol Rev 2020;72:829861.

29. Engert V, Koester AM, Riepenhausen A, Singer T. Boosting recovery rather than buffering reactivity: higher stress-induced oxytocin secretion is associated with increased cortisol reactivity and faster vagal recovery after acute psychosocial stress. Psychoneuroendocrinology 2016; 74:111-120.

30. Paivio SC, McCulloch CR. Alexithymia as a mediator between childhood trauma and self-injurious behaviors. Child Abuse Neglect 2004; 28:339-354.

31. McQuaid RJ, McInnis OA, Paric A, Al-Yawer F, Matheson K, Anisman H. Relations between plasma oxytocin and cortisol: The stress buffering role of social support. Neurobiol Stress 2016;3:52-60.

32. Amico JA, Mantella RC, Vollmer RR, Li X. Anxiety and stress responses in female oxytocin deficient mice. J Neuroendocrinol 2004;16:319324.

33. Nicolson NA, Davis MC, Kruszewski D, Zautra AJ. Childhood maltreatment and diurnal cortisol patterns in women with chronic pain. Psychosom Med 2010;72:471-480.

34. Gonzalez A, Jenkins JM, Steiner M, Fleming AS. The relation between early life adversity, cortisol awakening response and diurnal salivary cortisol levels in postpartum women. Psychoneuroendocrinology 2009; 34:76-86.

35. Heim C, Young LJ, Newport DJ, Mletzko T, Miller AH, Nemeroff CB. Lower CSF oxytocin concentrations in women with a history of childhood abuse. Mol Psychiatry 2009;14:954-958.

36. Tobon AL, Newport DJ, Nemeroff CB. The role of oxytocin in early life adversity and later psychopathology: a review of preclinical and clinical studies. Curr Treat Opt Psychiatry 2018;5:401-415.

37. Linnen AM, Ellenbogen MA, Cardoso C, Joober R. Intranasal oxytocin and salivary cortisol concentrations during social rejection in university students. Stress 2012;15:393-402.

38. Porges SW. Love: An emergent property of the mammalian autonomic nervous system. Psychoneuroendocrinology 1998;23:837-861. 
39. Plasencia G, Luedicke JM, Nazarloo HP, Carter CS, Ebner NC. Plasma oxytocin and vasopressin levels in young and older men and women: functional relationships with attachment and cognition. Psychoneuroendocrinology 2019;110:104419.

40. Hernandez VS, Hernandez OR, Perez de la Mora M, Gomora MJ, Fuxe $\mathrm{K}$, Eiden LE, et al. Hypothalamic vasopressinergic projections innervate central amygdala GABAergic neurons: Implications for anxiety and stress coping. Front Neural Circuits 2016;10:92.

41. Carter CS. The oxytocin-vasopressin pathway in the context of love and fear. Front Endocrinol (Lausanne) 2017;8:356.
42. Nandi DN, Banerjee G, Nandi S, Nandi P. Is Hysteria on the wane?: a community survey in West Bengal, India. Br J Psychiatry 1992;160:8791.

43. Zeev-Wolf M, Levy J, Ebstein RP, Feldman R. Cumulative risk on oxytocin-pathway genes impairs default mode network connectivity in trauma-exposed youth. Front Endocrinol 2020;11:335.

44. Altemus M, Sarvaiya N, Epperson CN. Sex differences in anxiety and depression clinical perspectives. Front Neuroendocrinol 2014;35:320330. 